\title{
Nerve growth factor-induced stimulation of p38 mitogen-activated protein kinase in PC12 cells is partially mediated via $G_{i / 0}$ proteins
}

\author{
Lisa Y. Yung, Prudence H. Tso, Eddy H.T. Wu, Jowie C.H. Yu, Nancy Y. Ip, \\ and Yung $H$. Wong $\dagger$
}

Department of Biochemistry, the Molecular Neuroscience Center, and the Biotechnology Research Institute, Hong Kong University of Science and Technology, Clear Water Bay, Kowloon, Hong Kong, China.

†To whom correspondence should be addressed: Department of Biochemistry, Hong Kong University of Science and Technology, Clear Water Bay, Kowloon, Hong Kong, China.

Tel: (852) 23587328 Fax: (852) 23581552

Email: boyung@ust.hk

Total number of pages: 30

Total number of figures: 6

Total number of words in the whole manuscript: 7855

Total number of words in the Abstract: 202

Total number of words in the Introduction: 504

Running title: $\mathrm{G}_{\mathrm{i} / \mathrm{o}}$ Proteins in NGF-Induced Stimulation of p38 MAPK

Keywords: ERK, G protein, nerve growth factor, p38 MAPK, PC12, Src 


\begin{abstract}
Differentiation of PC12 cells by nerve growth factor (NGF) requires the activation of various mitogen-activated protein kinases (MAPKs) including p38 MAPK. Accumulating evidence has suggested cross-talk regulation of NGF-induced responses by G protein-coupled receptors, thus we examined whether NGF utilizes $G_{i / o}$ proteins to regulate p38 MAPK in PC12 cells. Induction of p38 MAPK phosphorylation by NGF occurred in a time- and dose-dependent manner and was partially inhibited by pertussis toxin (PTX). NGF-dependent p38 MAPK phosphorylation became insensitive to PTX treatment upon transient expressions of G⿰$\alpha_{z}$ or the PTX-resistant mutants of $\mathrm{G \alpha}_{\mathrm{i} 2}$ and $\mathrm{G} \alpha_{\mathrm{oA}}$. Moreover, $\mathrm{G \alpha}_{\mathrm{i} 2}$ was co-immunoprecipitated with the TrkA receptor from PC12 cell lysates. To discern the participation of various signaling intermediates, PC12 cells were treated with a panel of specific inhibitors prior to the NGF challenge. NGF-induced p38 MAPK phosphorylation was abolished by inhibitors of Src (PP1, PP2, and SU6656) and MEK1/2 (U0126). Inhibition of the p38 MAPK pathway also suppressed NGF-induced PC12 cell differentiation. In contrast, inhibitors of JAK2, phospholipase C, protein kinase $\mathrm{C}$ and $\mathrm{Ca}^{2+} /$ calmodulin-dependent kinase II did not affect the ability of NGF to activate p38 MAPK. Collectively, these studies indicate that NGF-dependent p38 MAPK activity may be mediated via $\mathrm{G}_{\mathrm{i} 2}$ protein, Src, and the MEK/ERK cascade.
\end{abstract}




\section{Introduction}

Neuronal differentiation is a highly complex process which has to be precisely orchestrated through a number of signaling pathways. Defects in neuronal differentiation may result in various neuro-disorders including neuro-degenerative diseases. Rat pheochromocytoma12 (PC12) cells represent a model system to study neurite outgrowth, and their differentiation by nerve growth factor (NGF) requires the participation of various mitogen-activated protein kinases (MAPKs), including extracellular signal regulated protein kinase1/2 (ERK1/2), c-Jun N-terminal kinases (JNKs) and p38 MAPKs [1,2,3]. The dynamic balance of the activities of ERK1/2, JNK and p38 MAPK appears to be a determining factor in NGF-induced neurite outgrowth of PC12 cells [4].

Temporal responses of MAPKs are critical in coordinating growth factor-induced neuronal differentiation. Although both epidermal growth factor (EGF) and NGF can elicit MAPK phosphorylation, only NGF can induce PC12 cell differentiation through sustained activation of ERK1/2 and p38 MAPK [3, 5]. Inhibition of either NGF-induced ERK1/2 or p38 MAPK phosphorylation blocks neurite outgrowth in PC12 cells [6,7]. Upon NGF stimulation, ERK1/2 and p38 MAPK cascades regulate similar transcription factors such as the mitogen- and stress-activated protein kinase-1 (MSK1; [6]) and the cAMP-dependent response elementbinding proteins [8]. These studies reveal that NGF-dependent PC12 cell differentiation involves both ERK1/2 and p38 MAPK, and that the two pathways share some common features.

Detailed examinations of the mechanisms of growth factor-induced neuronal differentiation have insinuated the involvement of $G$ proteins. There is now a substantial body of literature on the role of pertussis toxin (PTX)-sensitive $\mathrm{G}_{\mathrm{i} / \mathrm{o}}$ proteins in neuronal differentiation. N1E-115 and LA-N-5 neuroblastomas as well as PC12 cells appear to employ $\mathrm{G}_{0}$ to mediate neurite outgrowth $[9,10,11,12]$. Moreover, expression of $\mathrm{G \alpha}_{\mathrm{i} 2}$ is increased in differentiated human neuroblastoma SH-SY5Y and PC12 cells [12,13], while activation of G $\alpha_{z}$ (a PTX- 
insensitive member of the $G_{i}$ family) significantly attenuates NGF-induced ERK1/2 phosphorylation and differentiation in PC12 cells [14]. Interestingly, signals arising from receptor tyrosine kinases and $\mathrm{G}_{\mathrm{i} / \mathrm{o}}$-coupled receptors are capable of integrating at the level of MAPKs [15]. In PC12 as well as airway smooth muscle cells, platelet-derived growth factor (PDGF) and NGF utilize $\mathrm{G}_{\mathrm{i} / \mathrm{o}}$ protein signaling pathways to phosphorylate ERK1/2, and that these pathways require clathrin-mediated endocytosis and phosphoinositide 3-kinase (PI3K) activation $[16,17,18]$. In addition, NGF-induced ERK1/2 phosphorylation involves G protein-coupled receptor kinase 2 (GRK2) and $\beta$-arrestin 1 [18]. The involvement of $G_{i / o}$ proteins in NGFinduced ERK1/2 phosphorylation and neurite outgrowth in PC12 cells is well established, whereas their contributions to NGF-regulated p38 MAPK pathway have yet to be investigated. Given the similarity between ERK1/2 and p38 MAPK signaling in the differentiation of PC12 cells, we tested the notion that $\mathrm{G}_{\mathrm{i} / \mathrm{o}}$ proteins are also involved in the stimulation of p38 MAPK by NGF.

\section{Materials and methods}

Materials. The rat $\mathrm{G \alpha}_{z}$ cDNA was a gift from Dr. Y. Kaziro (Tokyo Institute of Technology, Yokohama, Japan). The cDNA encoding chimeric $\mathrm{G \alpha}_{\mathrm{i} 2 / \mathrm{z}}$ was constructed as described previously [19]. The $\mathrm{G} \alpha_{\mathrm{oA}} \mathrm{CI}$ and $\mathrm{G} \alpha_{\mathrm{i} 2} \mathrm{GT}$ cDNAs were obtained from Guthrie (Sayre, PA, US). PC12 cells were obtained from American Type Culture Collection (ATCC CRL-1721; Rockville, MD). PTX and mouse NGF (mNGF 2.5S grade 2) were obtained from List Biological Laboratories (Campbell, CA) and Alomone labs (Israel), respectively. WHI-P131, AG490, KN62, W7, SB202190, SB203580, U73122, U73343, staurosporine, calphostin C, SU6656, U0126, Anthra[1,9-cd]pyrazol-6(2H)-one 1,9-pyrazoloanthrone SAPK/JNK Inhibitor II (SP600125), epidermal growth factor receptor inhibitor (AG1478), PDGF receptor blocker (AG1295), PP1, PP2 and PP3 were obtained from Calbiochem (CA, US). Antisera against p38 kinase, phospho- 
p38 MAPK (Thr $\left.{ }^{180} / \mathrm{Tyr}^{182}\right)$, phospho-Src $\left(\mathrm{Tyr}^{416}\right)$, phospho-TrkA $\left(\mathrm{Tyr}^{490}\right)$, ERK1/2 kinase and phospho-p44/42 MAPK (Thr ${ }^{202} / \mathrm{Tyr}^{204}$ ) were purchased from Cell Signaling Technology, (Beverly, MA, US). G $\mathrm{G}_{\mathrm{i} 2^{-}}$and $\mathrm{G} \alpha_{0}$-specific antisera, AS/7 and NEI810001EA were obtained

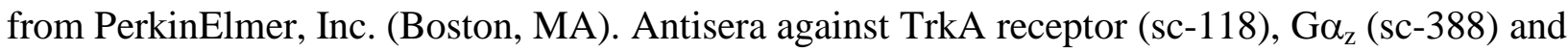
c-Src (sc-18) were purchased from Santa Cruz Biotechnology (Santa Cruz, CA). Plasmid purification columns were purchased from Qiagen Inc. (Hilden, Germany). Cell culture reagents were obtained from Life Technology (Grand Island, NY) and all other chemicals were purchased from Sigma Chemical (St. Louis, MO).

Cell culture and transfection. PC12 cells were cultured in Dulbecco’s modified Eagle’s medium (DMEM) supplemented with 6\% fetal calf serum (FCS; v/v), 6\% horse serum (HS) (v/v), $50 \mathrm{U} / \mathrm{ml}$ penicillin and $50 \mu \mathrm{g} / \mathrm{ml}$ streptomycin at $37^{\circ} \mathrm{C}$ in humidified air with $7.5 \% \mathrm{CO}_{2}$. PC12 cells were seeded onto 12-well plates at a density of $3 \times 10^{5}$ cells/well in $1 \mathrm{ml}$ of growth medium. 24 h later, PC12 cells were transiently transfected with Qiagen-purified cDNAs (0.5 $\mu \mathrm{g}$ of $\mathrm{G} \alpha_{z}, G \alpha_{z} \mathrm{QL}, \mathrm{G} \alpha_{\mathrm{oA}}, \mathrm{G} \alpha_{\mathrm{oA}} \mathrm{CI}, \mathrm{G} \alpha_{\mathrm{i} 2}, \mathrm{G} \alpha_{\mathrm{i} 2 / \mathrm{z}}, \mathrm{G} \alpha_{\mathrm{i} 2} \mathrm{GT}$ or pcDNA1) using LipofectAMINE 2000 according to the manufacturer's instructions. For the transient transfection process, $2 \%$ FCS DMEM without penicillin and streptomycin instead of serum free DMEM was used to culture PC12 cells. After transfection, PC12 cells were maintained in DMEM containing 6\% FCS and 6\% HS for $24 \mathrm{~h}$ prior to phosphorylation assay.

Primary cortical neuron cultures were prepared from embryonic day 18 (E18) rat embryos. Cortices were dissected in DMEM, dissociated in the same medium, and plated on poly-D-lysinecoated culture plates. Cells were cultured in neurobasal medium containing B27 supplement, 0.5 $\mathrm{mM}$ glutamine, penicillin (50 units/ml), and streptomycin $(100 \mu \mathrm{g} / \mathrm{ml})$. Cultures were incubated at $37{ }^{\circ} \mathrm{C}$ in a humidified atmosphere with $5 \% \mathrm{CO}_{2}$.

Detection of phosphorylated p38 MAPK. PC12 cells were cultured overnight with DMEM containing $0.1 \%$ FCS in the presence or absence of $100 \mathrm{ng} / \mathrm{ml} \mathrm{PTX.} \mathrm{The} \mathrm{cells} \mathrm{were}$ 
stimulated with or without various inhibitors for $15 \mathrm{~min}$ and subsequently with or without different concentrations of NGF for 1-30 min as indicated. Cell lysates were collected with 150 $\mu \mathrm{l}$ of $2 \%$ SDS sample buffer (50 mM Tris-Cl, $100 \mathrm{mM}$ dithiothreitol, 2\% SDS, 0.1\% bromophenol blue, 10\% glycerol; pH 6.8). $80 \mu \mathrm{l}$ of each cell lysate was resolved by $12 \%$ SDSpolyacrylamide gel electrophoresis, and then transferred to nitrocellulose membranes.

Primary cortical neuron cultures at DIV7 (7 days in vitro) were treated with B27 supplement free growth medium in the presence or absence of $100 \mathrm{ng} / \mathrm{ml} \mathrm{PTX} \mathrm{for} 24 \mathrm{~h}$. The cultures were then stimulated with $50 \mathrm{ng} / \mathrm{ml}$ NGF for $5 \mathrm{~min}$. Cell lysates were collected in $200 \mu \mathrm{l}$ of lysis buffer (50 mM Tris, pH 8.0, 1\% Nonidet P-40, 0.25\% deoxycholate, $1 \mathrm{mM} \mathrm{NaF,} 1 \mathrm{mM}$ $\mathrm{Na}_{2} \mathrm{VO}_{4}, 10 \%$ glycerol, $150 \mathrm{mM} \mathrm{NaCl}, 1 \mathrm{mM}$ EDTA, $10 \mu \mathrm{g} / \mathrm{ml}$ leupeptin, $10 \mu \mathrm{g} / \mathrm{ml}$ aprotinin, and $1 \mathrm{mM}$ PMSF). $30 \mu \mathrm{g}$ of each cell lysate was subjected to gel electrophoresis and Western blot analysis.

The presence of total p38 kinase, phospho-p38 MAPK, total ERK1/2 kinase, phosphop44/42 MAPK, total Src and phospho-Src were detected by anti-p38 kinase, phospho-p38 MAPK $\left(\mathrm{Thr}^{180} / \mathrm{Tyr}^{182}\right.$ ), ERK1/2 kinase and phospho-p44/42 MAPK ( $\mathrm{Thr}^{202} / \mathrm{Tyr}^{204}$ ), sc-18 and -Src $\left(\mathrm{Tyr}^{416}\right)$, respectively. Immune complexes were detected with horseradish peroxidase-conjugated secondary antibodies. Immunoblots were developed in the presence of enhanced chemiluminescence reagents, and the images detected in X-ray films were quantified by densitometric scanning using the Eagle Eye II still video system (Stratagene, La Jolla, CA). Values shown represent the mean \pm S.E. from three separate experiments. Representative blots were selected from a set of three independent experiments.

Co-immunoprecipitation. Confluent PC12 cells were cultured in DMEM containing $0.1 \%$ FCS for $24 \mathrm{~h}$. Subsequently, the cells from 4x100 mm plates were harvested in $2 \mathrm{ml}$ phosphate-buffered saline containing $1 \mathrm{mM}$ EDTA at $4^{\circ} \mathrm{C}$ and resuspended in $1 \mathrm{ml}$ ice-cold lysis buffer (50 mM Tris-HCl, containing 1 mM PMSF, 1 mM benzamidine-HCl, 1 mM EGTA, 1 
mM dithiothreitol, $200 \mu \mathrm{M} \mathrm{Na} \mathrm{VO}_{4}, 100 \mu \mathrm{M}$ phenylmethylsulfonyl fluoride, $2 \mu \mathrm{g} / \mathrm{ml}$ leupeptin, $4 \mu \mathrm{g} / \mathrm{ml}$ aprotinin, and $0.7 \mu \mathrm{g} / \mathrm{ml}$ pepstatin and $0.5 \% \mathrm{NP}-40 ; \mathrm{pH}$ 7.5). The supernatant was collected by centrifugation at $16,000 \mathrm{~g}$ for $5 \mathrm{~min}$ and incubated with or without an anti-TrkA

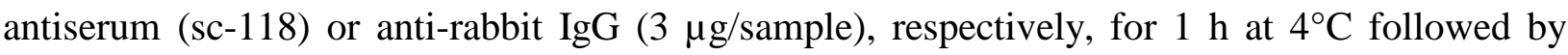
incubation with $30 \mu \mathrm{l}$ of protein A-agarose (50\% slurry) for a further $1 \mathrm{~h}$. The resulting immunoprecipitates were washed twice with ice-cold lysis buffer and resuspended in $80 \mu$ lysis buffer. Each sample was resolved by 12\% SDS-polyacrylamide gel electrophoresis and then transferred to nitrocellulose membranes. The presence of TrkA receptors, phospho-TrkA receptors, $\mathrm{G} \alpha_{\mathrm{i} 2}, \mathrm{G} \alpha_{0}$ and $\mathrm{G} \alpha_{\mathrm{z}}$ were detected by sc-118, phospho-TrkA ( $\left.\mathrm{Tyr}^{490}\right)$, AS/7, NEI810001EA and sc-388, respectively. 


\section{Results}

NGF-induced stimulation of $\mathbf{p 3 8}$ MAPK was partly mediated via PTX-sensitive $G_{i / 0}$ proteins. We began our study by examining the effects of SB203580 and SB202190, two inhibitors of p38 MAPK, on NGF-induced neurite extension in PC12 cells. As compared to the control, PC12 cells treated with NGF (5 ng/ml, 10 days) exhibited numerous protrusions of neurites (Fig. 1A). The NGF-induced neurite extension was suppressed in the presence of either SB203580 or SB202190 (Fig. 1A), suggesting that p38 MAPK might participate in NGF-induced neuronal differentiation. The ability of NGF to activate p38 MAPK in PC12 cells was then determined using anti-phospho-p38 MAPK antibodies. As illustrated in Fig. 1, NGF stimulated the activity of p38 MAPK in a time- and dose-dependent manner. When PC12 cells were challenged with either 5 or $50 \mathrm{ng} / \mathrm{ml}$ NGF for various time durations, activation of p38 MAPK was detected as early as 3 min of incubation and reached the peak activity at around 10 min (Fig. 1B). The p38 MAPK phosphorylation was maximally elevated by 5- to 7-fold above the basal level and was sustained for up to $30 \mathrm{~min}$ (Fig. 1B). At the optimum incubation time of $10 \mathrm{~min}$, treatment of PC12 cells with increasing concentrations of NGF resulted in a dose-dependent stimulation of p38 MAPK (Fig. 1C). The activity of p38 MAPK reached maximum levels of 6to 7 -fold above the basal at or higher than $50 \mathrm{ng} / \mathrm{ml}$ NGF. These results are consistent with a previous study [3].

Next, we examined the effect of PTX on NGF-induced activation of p38 MAPK. Pretreatment of PC12 cells with 100 ng/ml PTX for 24 h suppressed both 5 and 50 ng/ml NGFinduced p38 MAPK phosphorylation by 30-40\% (Fig. 2A), indicating the involvement of $\mathrm{G}_{\mathrm{i} / \mathrm{o}}$ proteins. Similarly, NGF-induced phosphorylation of p38 MAPK in primary cortical neurons was sensitive to PTX treatment (Fig. 2B). The observed PTX-sensitivity of NGF-induced p38 MAPK response in primary neuronal culture thus warrants further investigation into the mechanism of action. PC12 cells are known to express several forms of $G_{i / o}$ proteins $[11,12]$. We therefore attempted to determine the role of individual $\mathrm{G}_{\mathrm{i} / \mathrm{o}}$ proteins in NGF-regulated p38 MAPK activity. 
One of the approaches to assess the possible involvement of individual PTX-sensitive $\mathrm{G}_{\mathrm{i} / \mathrm{o}}$ proteins in a signaling pathway was to employ PTX-resistant mutants of the $\mathrm{G}_{\mathrm{i} / \mathrm{o}}$ proteins. Provision of PTX-resistant $\mathrm{G}_{\mathrm{i} / \mathrm{o}}$ mutants could confer PTX-resistance to the signaling pathway if the $G_{i / o}$ protein was indeed involved in the signal transduction. A PTX-resistant $G \alpha_{i 2} / G \alpha_{z}$ chimera $\left(G \alpha_{i 2 / z}\right)$ and a point mutant of $G \alpha_{o A}\left(G \alpha_{o A} \mathrm{CI}\right)$ have previously been successfully employed to study functional associations between $G$ protein-coupled receptors and $\mathrm{G \alpha}_{\mathrm{i} 2}$ and G $\alpha_{\mathrm{oA}}$, respectively $[19,20]$. In PC12 cells transfected with the cDNA of $\mathrm{G} \alpha_{\mathrm{i} 2 / \mathrm{z}}$, the NGF-induced p38 MAPK phosphorylation became completely PTX-insensitive (Fig. 2C); approximately 4-fold induction of p38 MAPK phosphorylation was observed in the absence or presence of PTX treatment. Expression of wild-type $\mathrm{G \alpha}_{\mathrm{i} 2}$ in PC12 cells did not confer PTX resistance to the NGF response (Fig. 2C); the NGF response was suppressed by $\sim 50 \%$ after PTX treatment. Similar results were obtained with the $\mathrm{G} \alpha_{\mathrm{oA}} \mathrm{CI}$ mutant. The NGF-induced p38 MAPK phosphorylation was completely insensitive to PTX treatment in PC12 cells expressing the $\mathrm{G} \alpha_{\mathrm{oA}} \mathrm{CI}$ mutant, whereas the same response was significantly attenuated ( 40\%) by PTX in cells transfected with the cDNA encoding wild-type $G \alpha_{0 A}$ (Fig. 2C). These experiments suggested that $G \alpha_{i 2 / z}$ and $\mathrm{G} \alpha_{\mathrm{OA}} \mathrm{CI}$ could mediate activation signals from NGF. Since many $\mathrm{G}_{\mathrm{i} / \mathrm{o}}$-coupled receptors also utilized $G_{z}$ for signal transduction [21], we asked if this PTX-insensitive member of the $G_{i}$ family could also participate in NGF-induced stimulation of p38 MAPK. In PC12 cells transiently expressing $G \alpha_{z}$, stimulation of p38 MAPK by NGF became insensitive to PTX treatment (Fig. 2C). Transfection of PC12 cells with the constitutively active form of $G \alpha_{z}\left(G \alpha_{z} Q L\right)$ had no effect on NGF-induced phosphorylation of p38 MAPK in the absence or presence of PTX (data not shown), presumably because $\mathrm{G} \alpha_{\mathrm{z}} \mathrm{QL}$ could not associate with its upstream regulator in its GTP-bound active state. It should be noted that transient expression of each distinct G $\alpha$ subunit in PC12 cells did not affect the ability of NGF to induce p38 MAPK phosphorylation (Fig. 2C 
upper panel). Collectively, these results indicate that NGF could utilize PTX-resistant $G_{z}$, PTXsensitive $G_{0 A}$ and $G_{i 2}$ in PC12 cells to regulate the activity of p38 MAPK.

We then attempted to demonstrate the physical association of TrkA receptors to endogenous $\mathrm{G}_{\mathrm{i} / \mathrm{o}}$ proteins. PC12 cells were treated with or without $5 \mathrm{ng} / \mathrm{ml}$ of NGF for $5 \mathrm{~min}$, and the TrkA receptors were immunoprecipitated from the cell lysates. The presence of TrkA receptors in the lysates and immunoprecipitates was confirmed by immunodetection with antiTrkA and anti-phospho-TrkA antisera (Fig. 3A). Despite the presence of $G \alpha_{i 2}, G \alpha_{o}$ and $G \alpha_{z}$ in the cell lysates of PC12 cells (Fig. 3A), only $\mathrm{G}_{\mathrm{i} 2}$ was co-immunoprecipitated with the TrkA receptor (Fig. 3); neither $\mathrm{G} \alpha_{0}$ nor $\mathrm{G} \alpha_{z}$ could be detected in the immunoprecipitates. Treatment of PC12 cells with NGF did not affect the ability of TrkA to associate with $\mathrm{G \alpha}_{\mathrm{i} 2}$ (Fig. 3A), suggesting that their interaction was independent of ligand binding. In order to reconfirm the ability of TrkA receptors to signal via $G \alpha_{\mathrm{i} 2}$, we used a dominant negative mutant of $\mathrm{G}_{\mathrm{i} 2}$ known as $\mathrm{G \alpha}_{\mathrm{i} 2} \mathrm{GT}$. Transfection of $\mathrm{G}_{\mathrm{i} 2} \mathrm{GT}$ into PC12 cells effectively inhibited the NGF-induced p38 MAPK phosphorylation (Fig. 3B), suggesting that functional interaction between TrkA and $\mathrm{Ga}_{\mathrm{i} 2}$ could indeed occur in PC12 cells.

ERK1/2 and Src are involved in NGF-regulated p38 MAPK activity. To map the signaling pathways linking TrkA receptor activation to p38 MAPK in PC12 cells, a panel of inhibitors was tested against NGF-induced p38 MAPK phosphorylation. Since p38 MAPK plays an essential role in cell survival [22], NGF may utilize signaling intermediates of the Ras/MAPK, JAK/STAT, and PI3K/Akt pathways, all of which contribute to cell survival, to regulate the activity of p38 MAPK. Indeed, $\mathrm{G}_{\mathrm{i} / \mathrm{o}}$ proteins are able to stimulate these three signaling pathways $[23,24]$. First, we examined the role of the Ras/Raf-1/ERK1/2 cascades in NGF-regulated p38 MAPK activity because activation of ERK1/2 activity appears to be a prerequisite for initiation of p38 MAPK phosphorylation [3,5]. Treatment of PC12 cells with $10 \mu \mathrm{M}$ U0126 (a MEK1/2 inhibitor) for 15 min significantly attenuated the NGF-induced p38 MAPK phosphorylation (Fig. 
4A). The inactive analogue of U0126 (U0124) at $10 \mu \mathrm{M}$ was also without effect. As expected, the JNK-specific inhibitor, SP600125, did not affect the NGF-induced p38 MAPK phosphorylation (Fig. 4A). Functional inhibition of NGF-induced phosphorylation of ERK and JNK by U0126 and SP600125, respectively, was demonstrated in separate experiments (Fig. 4B and C). On the other hand, U0124 had no effect on NGF-induced ERK activity (Fig. 4B). These results demonstrated that activation of ERK1/2 was essential for NGF-mediated p38 MAPK phosphorylation.

To examine whether JAK is involved in NGF-regulated p38 MAPK, PC12 cells were treated with or without $100 \mu \mathrm{M}$ AG490 for 15 min prior to stimulation by NGF (5 ng/ml, 10 min). Inhibition of JAK2 by AG490 did not affect the ability of NGF to induce p38 MAPK phosphorylation (Fig. 5A). Likewise, addition of specific inhibitors for the receptors of PDGF (10 $\mu \mathrm{M}$ AG1295) or EGF (50 nM AG1478) to PC12 cells was unable to inhibit NGF-stimulated p38 MAPK phosphorylation (Fig. 5A and data not shown), suggesting that G protein-mediated transactivation of EGF or PDGF receptors was not involved in NGF-induced activation of p38 MAPK.

A series of studies have revealed that PC12 cell differentiation involves activation of PKC via tyrosine phosphorylation by c-Src [25,26,27]. Hence, the roles of Src and PKC in NGFinduced p38 MAPK phosphorylation in PC12 cells were also investigated. Blockade of c-Src activity by treating PC12 cells with different Src inhibitors ( $25 \mu \mathrm{M}$ PP2 and $5 \mu \mathrm{M}$ SU6656) for 15 min substantially attenuated NGF-dependent p38 MAPK phosphorylation by 65\% (Fig. 5A), while treatment of PC12 cells with PKC inhibitors (100 nM calphostin C and $200 \mathrm{nM}$ staurosporine) for the same time period had no effect on NGF-induced p38 MAPK phosphorylation (Fig. 5B). It appeared that c-Src, but not PKC, was required for NGF-mediated p38 MAPK phosphorylation. The inhibitory effect of PP2 was specific because its inactive analogue, PP3, was without effect (Fig. 5A). Since Src is a common signaling intermediate for 
receptor tyrosine kinases and that it can be directly stimulated by activated $G \alpha_{i}$ [28], we asked if NGF-induced activation of Src requires PTX-sensitive G proteins. In PC12 cells, NGF stimulated the phosphorylation of c-Src kinase at residue $\mathrm{Tyr}^{416}$, as detected by an anti-phospho-Tyr ${ }^{416}$ c-Src antiserum (Fig. 5C). The NGF-induced Src activation was abolished by pretreatment with PTX, thus implicating the involvement of $\mathrm{G}_{\mathrm{i} / \mathrm{o}}$ proteins in this pathway.

Given that NGF-induced activations of ERK [18] and p38 MAPK (Fig. 2) both appeared to involve PTX-sensitive $\mathrm{G}_{\mathrm{i} / \mathrm{o}}$ proteins, the two pathways might share some common signaling intermediates. In CHO cells expressing TrkA receptors, NGF-elicited ERK1/2 phosphorylation is inhibited by U73122, an inhibitor of phospholipase C (PLC; [29]). Likewise, a number of studies have shown that $\mathrm{Ca}^{2+}$-dependent calmodulin kinase II (CaMKII) participates in neurite outgrowth [30] and in nicotine-induced ERK1/2 phosphorylation in PC12 cells [31]. We thus asked if PLC and CaMKII are also involved in NGF-induced stimulation of p38 MAPK. However, the addition of inhibitors against PLC (10 $\mu \mathrm{M}$ U73122) or CaMKII (10 $\mu \mathrm{M}$ KN62 and $50 \mathrm{nM}$ W7) to PC12 cells for 15 min had no effect on the ability of NGF to phosphorylate p38 MAPK (Fig. 5B). U73343, the inactive analogue of U73122, also had no effect on NGF-induced p38 phosphorylation (Fig. 5B). These results implied that both PLC and CaMKII were dispensable in the activation of p38 MAPK by NGF. By and large, in PC12 cells, NGFstimulated p38 MAPK activity was mediated via Src and ERK1/2.

\section{Discussion}

G protein-coupled receptors and receptor tyrosine kinases represent two of the largest families of cell surface receptors, and both families utilize highly sophisticated signaling networks with numerous loci for cross-talk [15]. One of such loci for signal integration is the MAPK cascade. Activation of p38 MAPK has been reported to participate in ligand-induced neuronal differentiation of PC12 cells [3,32]. Based on the sensitivity of NGF-induced 
phosphorylation of p38 MAPK to PTX, the present study demonstrates the involvement of $\mathrm{G}_{\mathrm{i} / \mathrm{o}}$ proteins in TrkA-mediated p38 MAPK activation. This conclusion is further supported by the fact that expressions of PTX-resistant versions of selected G $\alpha$ subunits can confer total PTX resistance to the NGF-induced response, and that $\mathrm{G \alpha}_{\mathrm{i} 2}$ can be co-immunoprecipitated with the TrkA receptor. These findings are in agreement with the PTX-induced abrogation of NGFmediated ERK signaling previously observed in PC12 cells [18]. The ability of TrkA to interact with $G$ proteins suggests that $G$ protein-coupled receptors can modulate NGF-induced responses. Cross-talk interactions of TrkA and G protein-coupled receptors in PC12 cells have indeed been demonstrated for lysophosphatidate receptor 1 [33, 34], purinergic $\mathrm{P}_{2} \mathrm{Y}_{2}$ [35], and muscarinic M4 [36] receptors.

The exact identity of the PTX-sensitive G protein(s) responsible for relaying part of the activation signal from TrkA to p38 MAPK has not been fully elucidated. Previous studies have established that $\mathrm{G} \alpha_{\mathrm{OA}}, \mathrm{G} \alpha_{\mathrm{i} 1}$ and $\mathrm{G} \alpha_{\mathrm{i} 2}$ are significantly upregulated in PC12 cells following NGFinduced neuronal differentiation $[10,12,37]$. Yet, another study revealed that activation of $G_{z}$ attenuates PC12 cell differentiation [14]. Both PTX-sensitive and -insensitive members of the $\mathrm{G}_{\mathrm{i} / \mathrm{o}}$ subfamily thus appear to directly or indirectly participate in neuronal differentiation of PC12 cells. The ability of $\mathrm{G \alpha}_{\mathrm{i} 2}$ to co-immunoprecipitate with TrkA suggests that $\mathrm{G \alpha}_{\mathrm{i} 2}$ can physically associate with the TrkA receptor, perhaps through adaptor proteins or as part of a macromolecular signaling complex. G $\alpha_{\mathrm{i} 2}$ has previously been reported to interact with pathways required for the differentiation of F9 teratocarcinoma cells [38]. The association of $\mathrm{G \alpha}_{\mathrm{i} 2}$ with the TrkA receptor does not appear to depend on the activation status of TrkA because application of NGF did not affect their interaction. Although $G \alpha_{o A}$ and $G \alpha_{z}$ did not co-mmunoprecipitate with TrkA, their involvement in NGF-induced p38 MAPK activation should not be simply dismissed. Hints of functional involvement of $G \alpha_{0 A}$ and $G \alpha_{z}$ in NGF-induced signaling can be gleaned from the responses obtained with PC12 cells overexpressing $\mathrm{G} \alpha_{\mathrm{oA}} \mathrm{CI}$ or $\mathrm{G} \alpha_{\mathrm{z}}$. Provision of PTX- 
resistant $\mathrm{G} \alpha_{\mathrm{oA}} \mathrm{CI}$ mutant or $\mathrm{G} \alpha_{\mathrm{z}}$ conferred total PTX-resistance to NGF-induced p38 MAPK phosphorylation, indicating that these $G$ proteins can functionally replace endogenous $G_{i / o}$ proteins which have been inactivated by the toxin. TrkA receptor may have a higher preference for $G_{i 2}$ in PC12 cells or that it may interact with $G_{0 A}$ and $G_{z}$ through a different mechanism. Potential linkages of TrkA receptor to $G_{0 A}$ and $G_{z}$ are especially interesting because these two $G$ proteins are predominately expressed in neural tissues. It should be noted that the functional G protein component which stimulates p38 MAPK activity is likely to be the G $\beta \gamma$ complex rather than the $G \alpha_{\mathrm{i} / \mathrm{o} / \mathrm{z}}$ subunit. Expression of $\mathrm{G} \beta \gamma$ or constitutively active $\mathrm{G} \alpha_{\mathrm{q}}$ in HEK 293 cells results in the activation of p38 MAPK [39], whereas similar reports have not been documented for any of the constitutively active $G \alpha_{i}$ subunits. Although the involvement of G $\beta \gamma$ in NGF-induced p38 MAPK activation has not been vigorously examined, the fact that NGF can employ multiple $\mathrm{G}_{\mathrm{i}}$ members for signal transduction supports this notion. Moreover, G $\beta \gamma$-dependent activation of p38 MAPK has recently been shown to mediate the differentiation of PC12 cells by Purkinje cell protein-2 [40]. The true identity of the $G_{i}$ protein which is responsible for relaying the PTXsensitive component of the NGF-induced p38 MAPK phosphorylation will require more definitive studies, perhaps using knock-down approaches with siRNA against individual G protein subunits.

Irrespective of which PTX-sensitive G protein is actually activated upon NGF treatment of PC12 cells, a fundamental question relates to how the activation signal is conveyed to the G protein. Reports on the functional interaction between growth factor receptors and $\mathrm{G}_{\mathrm{i} / \mathrm{o}}$ proteins are rapidly accumulating $[41,42]$. For instance, IGF-1 has been shown to activate $G_{i}$ to release the G $\beta \gamma$ complex, which in turn initiates activation of ERK1/2 [43,44]. The IGF-1 receptor appears to associate with a signaling complex composed of a regulator of G protein signaling (RGS) protein known as Ga interacting protein (GAIP) and the GAIP interacting protein C terminus (GIPC; [45]). The TrkA receptor can similarly utilize GIPC/GAIP to regulate MAPK. TrkA 
receptors and GAIP have been shown to bind to the PDZ domains of GIPC at different binding sites [46], and overexpression of GIPC reduces NGF-induced ERK1/2 phosphorylation. The association of TrkA receptor with GIPC/GAIP and the inhibition of ERK1/2 activity by GIPC suggest that GIPC may provide a link between TrkA and G protein signaling pathways [46]. It is noteworthy that GIPC has been reported to regulate the subcellular distribution of a membraneassociated, neurally enriched member of the semaphorin family of axon guidance signals [47]. More intriguingly, NGF can utilize RGS6 to regulate differentiation of PC12 cells [48]. TrkA receptors may also behave like PDGF receptors. PDGF receptors can tap into G proteinregulated signaling pathways by recruiting GRK2 and $\beta$-arrestin 1 , and efficient stimulation of MAPK can thus be achieved through signal integration $[18,49]$. Even though these findings do not provide obvious linkages between the TrkA receptor and $G_{i / o}$ proteins, they strengthen the possibility that $G$ proteins do indeed participate in mediating NGF-induced signals. There is in fact evidence to indicate the involvement of $\mathrm{G}_{\mathrm{i} / \mathrm{o}}$ proteins in NGF-induced phosphorylation of Akt [50] and tuberin [51] for the survival of PC12 cells as well as cortical neurons. The participation of $\mathrm{G}_{\mathrm{i} / \mathrm{o}}$ proteins allows $\mathrm{G}$ protein-coupled receptors to modulate NGF-mediated responses [52], as illustrated by the ability of muscarinic M4 receptor to augment NGF-induced pro-survival Akt signaling in PC12 cells [36].

Some of the signaling intermediates engaged in NGF-induced p38 MAPK activation in PC12 cells were also elucidated in the present study. Inhibitors against MEK1/2 and Src effectively suppressed the NGF-induced phosphorylation of p38 MAPK. The requirement for MEK1/2 implies the involvement of ERK1/2 in NGF-induced p38 MAPK activation. Indeed, p38 MAPK can be stimulated by the sequential activation of MEK/ERK/MKK3 [53]. Our observation that inhibition of Src can partially suppress the NGF-stimulated p38 MAPK phosphorylation in PC12 cells is consistent with the notion that NGF-induced stimulation of ERK1/2 and JNK are mediated via Src [54]. More interestingly, NGF-induced Src activation 
appeared to be routed through $\mathrm{G}_{\mathrm{i} / \mathrm{o}}$ proteins since Src phosphorylation was PTX-sensitive (Fig. 5C). Activation of Src family kinases is known to play a role in G protein-regulated signaling pathways [55]. $G_{i}$ proteins can activate Src directly via $G \alpha_{i}$ [28] or indirectly through $G \beta \gamma$ mediated binding of $\beta$-arrestin [56]. Moreover, many $\mathrm{G}_{\mathrm{i}}$-coupled receptors can stimulate JNK in a Src-dependent manner $[57,58]$ and Src is a crucial component linking other Go subunits to their downstream targets such as STAT3 and NFkB $[59,60]$. The involvement of Src downstream of $G_{i}$ proteins provides the means to activate p38 MAPK, probably via the small GTPases Rac and Cdc42 and then MKK3/6 (Fig. 6). Given that Src can bind to both TrkA and $\mathrm{G} \alpha_{\mathrm{i} 2}$, it may subserve the role of an adaptor in addition to being an effector of TrkA and $G \alpha_{\mathrm{i} 2}$.

TrkA has recently been shown to co-immunoprecipitate with calmodulin from PC12 cell lysates [61], thus raising the possibility that CaMKII may mediate part of the signals generated by NGF. Despite the reported involvement of CaMKII in the regulation of ERK1/2 [31], inhibition of CaMKII by KN62 had no effect on NGF-induced p38 MAPK phosphorylation. Other signaling molecules lying upstream of or parallel to CaMKII also appeared to be dispensable in the activation of p38 MAPK by NGF. They include PLC, calmodulin, and PKC. Hence, in terms of dependency on the PLC/PKC/CaMKII cascade, regulation of p38 MAPK by NGF is different from that of ERK activation [62].

In conclusion, the present study reveals that NGF employs a multitude of intermediates including $\mathrm{G}_{\mathrm{i}}$ proteins, c-Src, and ERK1/2 to activate p38 MAPK in PC12 cells, the map of signal routing is far from complete (Fig. 6). However, the linkage between G proteins and p38 MAPK certainly needs further mapping. Among the obvious candidates are the small GTPases such as Cdc42, Rac and Rho that are known to be activated by NGF [63]. Additionally, Gi/o proteins have been shown to regulate neurite outgrowth via the small GTPases Rap1 and Ral [64]. These small GTPases may act as points of convergence for both TrkA receptors and $\mathrm{G}_{\mathrm{i} / \mathrm{o}}$ proteins (Fig. 6). Like many crucial biological processes, complexity in the coordination of neuronal 
differentiation ensures that the course of action can proceed despite minor defects. We have preliminary data to suggest that PTX and inhibitors of Src can only partially suppress NGFinduced neurite outgrowth in PC12 cells. Since the other member of the MAPK family, JNK, can also be activated by NGF [8], it remains to be determined whether NGF utilizes similar signaling pathways to stimulate the activity of JNK in PC12 cell differentiation. 


\section{Acknowledgements}

This work was supported in part by grants from the Research Grants Council of Hong Kong (HKUST 3/03C), the University Grants Committee (AoE/B-15/01), and the Hong Kong Jockey Club. NYI and YHW were recipients of the Croucher Senior Research Fellowship. 


\section{Abbreviations used}

DMEM, Dulbecco’s modified Eagle’s medium; EGF, epidermal growth factor; ERK, extracellular signal-regulated protein kinases; G protein, guanine nucleotide-binding regulatory protein; GRK2, G protein-coupled receptor kinase 2; JNK, c-Jun N-terminal kinase; MAPK, mitogen-activated protein kinase; NGF, nerve growth factor; PDGF, platelet-derived growth factor; PI3K, phosphatidylinositol-3 kinase; PTX, pertussis toxin; PKC, protein kinase C; PLC, phospholipase C. 


\section{References}

1. M. Fukuda, Y. Gotoh, T. Tachibana, K. Dell, S. Hattori, Y. Yoneda, E. Nishida, Oncogene (1995)11:239-244.

2. S. Leppa, R. Saffrich, W. Ansorge, D. Bohmann, EMBO J. (1998) 17: 4404-4413.

3. T. Morooka, E. Nishida, J. Biol. Chem. (1998) 273: 24285-24288.

4. S.D. Santos, P.J. Verveer, P.I. Bastiaens, Nat. Cell Biol. (2007) 9: 324-330.

5. L. New, Y. Li, B. Ge, H. Zhong, J. Mansbridge, K. Liu, J. Han, J. Cell. Biochem. (2001) 83: 585-596.

6. M. Deak, A.D. Clifton, L.M. Lucocq, D.R. Alessi, EMBO J (1998) 17: 4426-4441.

7. Y. Sakai, H. Hashimoto, N. Shintani, S. Tomimoto, K. Tanaka, A. Ichibori, M. Hirose, A. Baba, Biochem. Biophys. Res. Commun. (2001) 285: 656-661.

8. J. Xing, J.M. Kornhauser, Z. Xia, E.A. Thiele, M.E. Greenberg, Mol. Cell. Biol. (1998) 18: 1946-1955.

9. P.Brabet, C. Pantaloni, M. Rodriguez, J. Martinez, J. Bockaert, V. Homburger, J. Neurochem. (1990) 54: 1310-1320.

10. S. Andreopoulos, P.P. Li, J.J. Warsh, Brain Research. Developmental Brain Research. (1995) 88:30-36.

11. X. Li, S.M. Mumby, A. Greenwood, R.S. Jope, J. Neurochem. (1995) 64: 1107-1117.

12. M. Zubiaur, E.J. Neer, J. Neurosci. Res. (1993) 35: 207-217.

13. H. Ammer, R. Schulz, J. Neurochem. (1994) 62: 1310-1318.

14. J. Meng, P.J. Casey, J. Biol. Chem. (2002) 277: 43417-43424.

15. V.L. Lowes, N.Y. Ip, Y.H. Wong, NeuroSignals (2002) 11: 5-19.

16. A.M. Conway, S. Rakhit, S. Pyne, N.J. Pyne, Biochem. J. (1999) 337: 171-177.

17. S. Rakhit, S. Pyne, N.J. Pyne, Mol. Pharmacol. (2000) 58:413-420.

18. S. Rakhit, S. Pyne, N.J. Pyne , Mol. Pharmacol. (2001) 60: 63-70. 
19. R.C. Tsu, M.K. Ho, L.Y. Yung, S. Joshi, Y.H. Wong, Mol. Pharmacol. (1997) 52: 38-45.

20. A. Wise, M.A.Watson-Koken, S. Rees, M. Lee , G. Milligan, Biochem. J. (1997) 321: 721728.

21. M.K. Ho, Y.H. Wong, Oncogene. (2001) 20: 1615-1625.

22. Z. Xia, M. Dickens, J. Raingeaud, R.J. Davis, M.E. Greenberg, Science (1995) 70: 13261331.

23. J. Alblas, E. J. van Corven, P.L. Hordijk, G. Milligan, W.H. Moolenaar, J. Biol. Chem. (1993) 268: 22235-22238.

24. P.T. Ram, C.M. Horvath, R. Iyengar, Science (2000) 287: 142-144.

25. E.S. Coleman, M.W. Wooten, J. Mol. Neurosci. (1994) 5: 39-57.

26. M.W. Wooten, M.L. Seibenhener, G. Zhou, M.L. Vandenplas, T.H. Tan, Cell Death \& Differentiation (1999) 6: 753-764.

27. M.W.Wooten, M.L. Vandenplas, M.L. Seibenhener, T. Geetha, M.T. Diaz-Meco, Mol. Cell. Biol. (2001) 21: 8414-8427.

28. Y.C. Ma, J. Huang, S. Ali, W. Lowry, X.Y. Huang, Cell (2000) 102: 635-646.

29. A. Zapf-Colby, J. Eichhorn, N.J. Webster, J.M. Olefsky, Oncogene (1999) 18: 4908-4919.

30. M. Solem, T. McMahon, R.O. Messing, J. Neurosci. (1995) 15: 5966-5975.

31. H. Nakayama, T. Numakawa, T. Ikeuchi, H. Hatanaka, J. Neurochem. (2001) 79: 489-498.

32. K.M. Jung, K.S. Park, J.H. Oh, S.Y. Jung, K.H. Yang, Y.S. Song, D.J. Son, Y.H. Park, Y.P. Yun, M.K. Lee, K.W. Oh, J.T. Hong, Mol. Pharmacol. (2003) 63: 607-616.

33. N.A. Moughal, C. Waters, B. Sambi, S. Pyne, N.J. Pyne, Cell. Signal. (2004) 16: 127-136.

34. N.A. Moughal, C.M. Waters, W.J. Valentine, M. Connell, J.C. Richardson, G. Tigyi, S. Pyne, N.J. Pyne, J. Neurochem. (2006) 98: 1920-1929.

35. D.B. Arthur, K. Akassoglou, P.A. Insel, Proc. Natl. Acad. Sci. U.S.A. (2005) 102: 1913819143. 
36. E.H.T. Wu, Y.H. Wong, Cell. Signal. (2006) 18: 285-293.

37. X. Li, R.S. Jope, Brain Research (1997) 759: 213-220.

38. D.C. Watkins, G.L. Johnson, C.C. Malbon, Science (1992) 258: 1373-1375.

39. J. Yamauchi, G. Tsujimoto, Y. Kaziro, H. Itoh, J. Biol. Chem. (2001) 276: 23362-23372.

40. J. Guan, Y. Luo, B.M. Denker, Biochem. J. (2005) 392: 389-397.

41. P.L. Rothenberg, C.R. Kahn, J. Biol. Chem. (1988) 263: 15546-15552.

42. L.M. Luttrell, E. Kilgour, J. Larner, G, Romero, J. Biol. Chem. (1990) 265: 16873-16879.

43. L.M. Luttrell, T. Van Biesen, B.E. Hawes, W.J. Koch, K. Touhara, R.J. Lefkowitz, J. Biol. Chem. (1995) 270: 16495-16498.

44. H. Hallak, E.M. Seiler, J.S. Green, B.N. Ross, R. Rubin, J. Biol. Chem. (2000) 275: 22552258.

45. R.A. Booth, C. Cummings, M. Tiberi, X.J. Liu, J. Biol. Chem. (2002) 277: 6719-6725.

46. X. Lou, H. Yano, F. Lee, M.V. Chao, M.G.Farquhar, Mol. Biol. Cell (2001) 12: 615-627.

47. L.H. Wang, R.G. Kalb, S.M. Strittmatter, J. Biol. Chem. (1999) 274: 14137-14146.

48. Z. Liu, T.K. Chatterjee, R.A. Fisher, J. Biol. Chem. (2002) 277: 37832-37839.

49. F. Alderton, S. Rakhit, K.C. Kong, T. Palmer, B. Sambi, S. Pyne, N.J. Pyne, J. Biol. Chem. (2001) 276: 28578-28585.

50. E.H.T. Wu, Y.H. Wong, Cell. Signal. (2005a) 17: 881-890.

51. E.H.T. Wu, Y.H. Wong, Mol. Pharmacol. (2005b) 67: 1195-1205.

52. E.H.T. Wu, K.K.H. Wu, Y.H. Wong, NeuroSignals (2007) 15: 217-227.

53. W. Wang, J.X. Chen, R. Liao, Q. Deng, J.J. Zhou, S. Huang, P. Sun, Mol. Cell. Biol. (2002) 22: 3389-3403.

54. R.L. Malek, Z. Nie, V. Ramkumar, N.H. Lee, J. Biol. Chem. (1999) 274: 35499-35504.

55. M. Nagao, J. Yamauchi, Y. Kaziro, H. Itoh, J. Biol. Chem. (1998) 273: 22892-22898.

56. L.M. Luttrell, R.J. Lefkowitz, J. Cell Sci. (2002) 115: 455-465. 
57. A.S. Chan, F.P. Lai, R.K. Lo, T.A.Voyno-Yasenetskaya, E.J. Stanbridge, Y.H. Wong, Cell. Signal. (2002) 14: 249-257.

58. A.Y. Kam, A.S. Chan, Y.H. Wong, J. Neurochem. (2003) 84: 503-513.

59. R.K.H. Lo, H. Cheung, Y.H. Wong, J. Biol. Chem. (2003) 278: 52154-52165.

60. A.M.F. Liu, Y.H. Wong, J. Biol. Chem. (2004) 279: 53196-53204.

61. M. Llovera, Y. de Pablo, J. Egea, M.Encinas, S. Peiró, D. Martín-Zanca, N. Rocamora, J.X. Comella, J Neurochem. (2004) 88(2):422-33.

62. N. Agell, O. Bachs, N. Rocamora, P. Villalonga, Cell. Signal. (2002) 14: 649-654.

63. A. Patapoutian, L.F. Reichardt, Cur. Opin. Neurobiol. (2001) 11: 272-280.

64. J.C. He, S.R. Neves, J.D. Jordan, R. Iyengar, Can. J. Physiol. Pharmacol. (2006) 84: 687694. 
Figure 1. NGF stimulated p38 kinase activity in PC12 cells. A. PC12 cells were seeded into $35 \mathrm{~mm}$ plates at 10,000 cells/well in $2 \mathrm{ml}$ assay medium (0.1\% FCS/DMEM). Subsequently, the cells were treated with $5 \mathrm{ng} / \mathrm{ml} \mathrm{NGF}$ in the absence or presence of an inhibitor (10 $\mu \mathrm{M}$ SB203580 or SB202190); growth medium and inhibitors were replaced every 2 days. Micrographs of PC12 cells were taken with a light microscope (20 X) on day 10. B. PC12 cells were seeded into 12-well plate and then grown in reduced serum $(0.1 \%$ FCS $)$ for $24 \mathrm{~h}$. On the second day, the cells were challenged with $1 \mathrm{ml}$ serum free medium containing 5 or $50 \mathrm{ng} / \mathrm{ml}$ NGF for different time durations as indicated. PC12 cells were treated with $5 \mathrm{ng} / \mathrm{ml}$ (solid circle) or $50 \mathrm{ng} / \mathrm{ml}$ (open circle) of NGF. C. PC12 cells were treated as in B but with varying concentrations of NGF for $10 \mathrm{~min}$. For $\mathbf{B}$ and $\mathbf{C}$, the cell lysates were analyzed for p38 MAPK phosphorylation as described in Materials and Methods. Values are the mean \pm S.E. from three separate experiments while only representative Western blots are shown.

Figure 2. NGF-induced p38 phosphorylation involves $G_{i / o}$ proteins. A. PC12 cells were seeded into 12-well plates and then cultured in reduced serum (0.1\% FCS) with or without PTX (100 ng/ml) for $24 \mathrm{~h}$. PC12 cells were incubated with $1 \mathrm{ml}$ serum free medium containing 5 or $50 \mathrm{ng} / \mathrm{ml} \mathrm{NGF}$ for $10 \mathrm{~min}$. B. Primary cortical neuron cultures at DIV7 were seeded into 6-well plates and then replenished with the growth medium without B27 supplement in the presence or absence of $100 \mathrm{ng} / \mathrm{ml}$ PTX for $24 \mathrm{~h}$. The cultures were then stimulated with $50 \mathrm{ng} / \mathrm{ml} \mathrm{NGF}$ for 5 min and their cell lysates analyzed for p38 MAPK phosphorylation. C. PC12 cells were seeded into 12-well plate and transfected with cDNAs encoding $G \alpha_{z}, G \alpha_{o A}, G \alpha_{o A} C I, G \alpha_{i 2}$, or $G \alpha_{i 2 z}$ as indicated. Transfected PC12 cells were treated as in A and challenged with 5 ng/ml NGF for 10 min. Cell lysates were analyzed for p38 MAPK phosphorylation. *NGF significantly stimulated p38 phosphorylation (Dunnett $t$ test, $P<0.05$ ). "NGF-induced p38 phosphorylation was 
significantly reduced by PTX treatment (Dunnett $t$ test, $P<0.05$ ). Values are the mean \pm S.E. from three separate experiments while only representative Western blots are shown.

Figure 3. Physical association of TrkA receptors to endogenous $G_{i 2}$. A. Coimmunoprecipitation of TrkA receptors and $\mathrm{G} \alpha_{\mathrm{i} 2}$. PC12 cells in $100 \mathrm{~mm}$ plates were cultured with reduced serum $(0.1 \%$ FCS $)$ for $24 \mathrm{~h}$ and then treated in the absence or presence of $5 \mathrm{ng} / \mathrm{ml}$ NGF for 5 min. Total cell lysates were collected and the presence of TrkA, phospho-TrkA, G $\alpha_{i 2}$, $G \alpha_{0}$ and $G \alpha_{z}$ was detected by specific antisera. Detergent-soluble cell lysates were collected and incubated with anti-TrkA or anti-IgG as described in Materials and Methods. The immunoprecipitates were then probed with the indicated antisera by western blotting. B. PC12 cells were transfected with cDNAs encoding $G \alpha_{\mathrm{i} 2}$ or $\mathrm{G \alpha}_{\mathrm{i} 2} \mathrm{GT}$ and treated with PTX and NGF as in legend to Fig. 2C. Cell lysates were analyzed for p38 MAPK phosphorylation. *NGF significantly stimulated p38 phosphorylation (Dunnett $t$ test, $P<0.05$ ). ${ }^{\#}$ NGF-induced p38 phosphorylation was significantly reduced by PTX treatment (Dunnett $t$ test, $P<0.05$ ). Values are the mean \pm S.E. from three separate experiments while only representative Western blots are shown.

Figure 4. NGF-induced p38 MAPK phosphorylation employed ERK1/2. A. PC12 cells were treated as in the legend to Fig. $1 \mathrm{C}$ in the absence or presence of a specific inhibitor $(10 \mu \mathrm{M}$ each of U0124, U0126 or SP600125) as indicated for $15 \mathrm{~min}$ and subsequently challenged with 5 ng/ml NGF for 10 min. Cell lysates were analyzed for p38 MAPK phosphorylation. B. PC12 cells were treated with either U0126 or SP600125 as in A before assaying for ERK and JNK phosphorylation with specific antisera. *NGF significantly stimulated p38 MAPK, ERK1/2 or JNK phosphorylation (Dunnett $t$ test, $P<0.05$ ). " NGF-induced p38 MAPK, ERK1/2 or JNK phosphorylation was significantly suppressed by the respective inhibitors (Dunnett $t$ test, 
$P<0.05)$. Values are the mean \pm S.E. from three separate experiments while only representative Western blots are shown.

Figure 5. NGF employed c-Src to activate p38 MAPK. A. PC12 cells were treated as in the legend to Fig. 4A in the absence or presence of various inhibitors (100 $\mu \mathrm{M}$ AG490, $10 \mu \mathrm{M}$ AG1295, $5 \mu \mathrm{M}$ SU6656, $25 \mu \mathrm{M}$ PP1, $25 \mu \mathrm{M}$ PP2 or $25 \mu \mathrm{M}$ PP3) before assaying for p38 MAPK phosphorylation. B. PC12 cells were treated as in the legend to Fig. 4A in the absence or presence of a specific inhibitor (10 $\mu \mathrm{M}$ KN62, $50 \mathrm{nM}$ W7, $10 \mu \mathrm{M}$ U73122, $10 \mu \mathrm{M}$ U73343, 200 nM staurosporine or $100 \mathrm{nM}$ calphostin C) before assaying for p38 MAPK phosphorylation. C. PTX abolished NGF-activated c-Src phosphorylation. PC12 cells were treated as in the legend to Fig. 2A prior to stimulation with $5 \mathrm{ng} / \mathrm{ml}$ NGF for 10 min. NGF-induced c-Src phosphorylation was determined with specific antisera. *NGF significantly stimulated p38 MAPK phosphorylation (Dunnett $t$ test, $P<0.05$ ). " NGF-induced p38 MAPK or c-Src phosphorylation was significantly inhibited by the respective inhibitors (Dunnett $t$ test, $P<0.05$ ). Values are the mean \pm S.E. from three separate experiments while only representative Western blots are shown.

Figure 6. A hypothetical mechanistic model for NGF-induced p38 MAPK signaling pathway. NGF activates p38 MAPK activity in PC12 cells employing $\mathrm{G}_{\mathrm{i} 2}$, Src, and MEK1/2. Solid-lined arrows illustrate findings based on previous studies. Dash-lined arrows indicate that the interactions are either putative or involve multiple steps. C3G, a guanine nucleotide exchange factor; Crk, a protein adaptor; GAIP, G $\alpha$-interacting protein; GIPC1, GAIP interacting protein 1; Rap1 and Ras, small GTP binding proteins; B-Raf, MAPK kinase kinase; MEK1/2, MAPK kinase; RhoGEF, a guanine nucleotide exchange factor of Rho; RhoA and Rac/cdc42, members of small GTPases of the Rho family; MEKK1-4 and MLK (mixed lineage kinases), membrane proximal MAPK kinase kinases; MKK4 (SER), the SAPK/JNK kinase; MKK3/6, 
p38 MAPK kinase. The experimental evidence supporting individual pathways and the interactions between their intermediates are described in the text. 